\title{
Integrating Process Modeling and Simulation with Benchmarking using a Business Process Management System for Local Government
}

\author{
S. P. Gayialis, G. A. Papadopoulos, S. T. Ponis, P. Vassilakopoulou, and I. P. Tatsiopoulos
}

\begin{abstract}
Recently, the strategic approaches of public sector organizations are reevaluated in order to achieve modern effective operations and provide better services to their customers (citizens and businesses). Business Process Management (BPM) solutions are recognized as essential tools for public services transformation, as they enable public organizations to be more efficient, to meet business challenges rapidly and flexibly, and to improve the customers experience by resolving incidents and responding to requests in a timely fashion. Within this context, this paper describes the development of a BPM System (BPMS) as a part of a web-based integrated system for benchmarking, monitoring, simulation and redesigning processes. This system will be deployed initially in Municipalities and later on in several Greek government agencies, in order to offer more efficient, personalized and consistent services to citizens and businesses, in a reduced operational cost. The paper presents the methodological approach followed for BPMS development. It also highlights system's functionality and its usefulness in process design, benchmarking, redesign and continuous improvement.
\end{abstract}

Index Term-Business process management system, public sector services, benchmarking, business process improvement.

\section{INTRODUCTION}

Public Sector Organizations are facing the challenge of delivering high quality services that meet local needs, efficiently. A variety of computer based support tools for performance management and process improvement has been proposed and t[ried out in governmental settings [1]-[3].

Business Process Management (BPM) solutions are widely spread in private sector offering many advantages to those companies that adapt them. The key benefits of BPM software solutions include the increased business efficiency, rapid deployment of compliance and process changes, improved employee productivity and increased business engagement [4]. BPM systems also recognized as essential tools for public services transformation, as they enable public organizations

Manuscript received February 4, 2015; revised August 25, 2015. This work is a part of the research project "Public Services' Benchmarking, Design, Monitoring \& Evaluation Platform (PSB-DMEP)" in research action: "Synergasia", which is implemented under the Operational Programme: Competitiveness and Entrepreneurship (OPCE II), NSRF 2007-2013 and is co-funded by European Union (European Regional Development Fund) and Greek Government.

S. P. Gayialis, G. A. Papadopoulos, S. T. Ponis, and I. P. Tatsiopoulos are with the School of Mechanical Engineering, National Technical University of Athens, 15780, Greece (e-mail: sotga@central.ntua.gr, gpapado@mail.ntua.gr, staponis@central.ntua.gr, itat@central.ntua.gr).

P. Vassilakopoulou is with Faculty of Mathematics and Natural Sciences Department of Informatics, University of Oslo (e-mail: xvasil@ifi.uio.no). to be more efficient, to meet business challenges rapidly and flexibly, and to improve the citizen experience by resolving incidents and responding to requests in a timely fashion [5].

A BPM system for public sector is being described in the paper, as the core system of an integrated system being developed in the context of "PSB-DMEP" (Public Services' Benchmarking, Design, Monitoring, \& Evaluation Platform) research project in Greece (www.psb-dmep.gr). Research project aims to improve the capabilities of municipalities to renew their processes by enhancing design capabilities. The project's outcome is an integrated system (consisting of four systems) for business process management and benchmarking.

The BPM system is the core system of PSB-DMEP, which will be deployed initially in Local government (Municipalities) and later on in several Greek government agencies, in order to offer more efficient, personalized and consistent services to citizens and businesses, in a reduced operational cost. The other three systems (as illustrated in Fig. 4) include: i) the Benchmarking system that will be used by the public sector organizations in order to measure, evaluate and benchmark the performance of their business processes via KPI's and to receive detailed and customizable performance reports, ii) the supplement Management by Objectives (MBO) system to support the application of MBO methodology in Greek local government, as it is described in the existing legislative framework and finally iii) an e-Participation system for documentation, communication and social networking, acting as the integrated system's central point of communication with citizens and businesses, emphasizing on their feedback for public services improvement.

Through the Business Process Management System (BPMS), business processes are being modeled, monitored, simulated (reevaluating their performance indicators and their benchmark) and reengineered in order to be constantly improved. The system utilizes the basic principles of Business Process Management and the functionality of process modeling and simulation tools so as to fully cover the operational needs of public sector services.

The remainder of the paper is divided into four parts. The first part deals with the background of business process management systems, especially in public sector. The second part describes the methodological approach followed for BPM system design and development. The third part describes the integrated system, highlights BPM system functionality and its interoperability with benchmarking system. Finally, the fourth part concludes with a discussion on 
the research outcomes, highlighting on system's benefits and its value in process design and redesign of public services.

\section{BUSINESS PROCESS MANAGEMENT SYSTEMS AND Process IMPROVEMENT IN PUBLIC SECTOR}

A Business Process Management (BPM) system is characterized as the software applications that "enable the modeling, execution, technical and operational monitoring, and user representation of business processes and rules, based on integration of both existing and new information systems functionality that is orchestrated and integrated via services"[6]). BPM system adoption is strongest in sectors that were hit hardest during the economic downturn, such as financial services, business services and construction, manufacturing, public sector and healthcare, retail and wholesale, and telecommunications [4]. Especially in the public administration, BPM has gain significant attention during the last years and many Governments are taking advantage of multiple benefits that BPM software solutions offer [7].

The Benefits of BPM application in Public Sector include [8], [9]: i) increased effectiveness and efficiency achieved from restructuring the organization along cross-functional processes, ii) better integration perspectives and priorities with resource management, utilization of creative and innovative approaches to enhancing organizational performance, effective implementation of modern systems and standard software; i.e. most new implementations are process-oriented.

There are various cases of BPM implementation in public administration, like the case of Denmark. Some years ago, Denmark was facing problems in the underlying organizational and administrative structures of its Municipalities, as they weren't able to offer the same level of service and meet the growing citizens' demands. To address these problems, Local Government Denmark interest group was formed in 2006, with the participation of all the 98 Denmark municipalities, and launched an effort to capture and define processes, focusing on process modeling. By 2010, LGDK Business Process Bank contained 250 key processes, 50 sub-processes and 100 associated best practices. All processes were modeled with BPMN methodology and are accessible from all municipalities [10]. Another example of successful use of BPM comes from Sweden; emphasis was given to improve care services provided to vulnerable groups through the development of electronic services. The Swedish Agency for Research and Innovation for Sustainable Growth funded "Open Social Services" action, which undertook the analysis and design of e-services, and the feasibility study on supported open source software. The outcome of the project was the development of 3 user-friendly electronic services, where the used BPM software played an essential role in their designing and coordination, as also in increasing the system's flexibility and transparency [11].

As performance management in the public sector is more important than ever, new business processes supported by technology-driven tools, can be developed and integrated to support the strategic goals, the measurement of progress and the accountability to the public. Most of technology based support tools for performance management and process improvement have been developed for enhancing control and 'upwards accountability' [12] rather than preparing organizations for responsiveness by promoting learning, creativity and the enhancement of dynamic capabilities [13], [14].

The need to find a good balance between preparing for responsiveness and preparing for accountability is prominent in local government where the close relationship between citizens, elected officials and line management creates tensions. Furthermore, it is difficult to replicate successful solutions from other similar organizations as differences among different local communities have to be clearly acknowledged and respected. Finally, due to their public character, inclusivity of multiple stakeholders and bottom-up flows are important. Local government challenges are aggravated become with the advancement of technology.

Local government organizations are caught amidst a sweeping wave of changes and new possibilities, calling for a rethink and redesign of work. According to the Organization for Economic Co-operation and Development (OECD), $42 \%$ of workers in OECD countries reported to have experienced "the introduction of new processes or technologies in the workplace in the previous three years" [15]. The effective renewal of processes and/or technologies cannot be a simple 'import' or 'copy' of solutions that have been successful elsewhere. New processes and technologies become operational through their adaptation to the specificities of contexts, practices, and institutional visions. Instead of pushing prefabricated solutions to organizations that prove unable to follow current developments, it is important to put in place mechanisms that will enhance their capacity for renewal.

\section{BPM SYSTEM DESIGN AND DEVELOPMENT}

BPM system presented in this paper is part of an integrated system for benchmarking of public services, evaluation of business processes performance and design or redesign front-end and back-office business processes, using business process modeling and simulation tools. This system is being developed in the context of a research project in Greece. The project participants include a major technological University responsible for the theoretically informed analysis and design of the new system, an IT company coordinating the project and implementing the system, an umbrella organization of municipalities under the 'Digital Cities' initiative and a major municipality. Additionally, the project is supported by a municipal spin-off company and a second IT company participating in the project as a subcontractor.

The new BPM system is designed to include modeling and simulation functionality to trigger experimentation and exploration activities that could not be possible under the strict regimes of public sector: 'models and simulations are more concrete than transcendental ideas and can play an experimental role by preparing and executing what-if scenarios providing, in that sense, a window to the future, a reality that is yet to come, a new type of reality' [16]. Experimentation can trigger learning leading to refinement of concepts or to the abandonment of concepts and their 
fundamental recreation [17].

The BPM system's key objectives are to manage the business processes throughout their whole lifecycle and to interchange data with the rest sub-systems of the research project's integrated information system. In order to achieve those goals during the design and development of the BPM system, a methodological approach was created, consisted of seven methodological steps. This methodology is adapted in the needs of the research project but its steps are general enough to be applied in other cases of BPM system design and implementation for public sector. The methodological approach is based on key concepts for systems design and development, like those described in [18]-[21]. BPM software market research (step 1) and BPM Software Evaluation - Selection of Suitable Software (step 6) include some "go-not-go" criteria which are usually important in system design and development for public sector (like the use of open source software or the data exchange with different existing systems in several public organizations). Fig. 1 illustrates the methodological approach for design and development of public services BPM system, while the key activities of every methodological step are described in the next paragraphs.

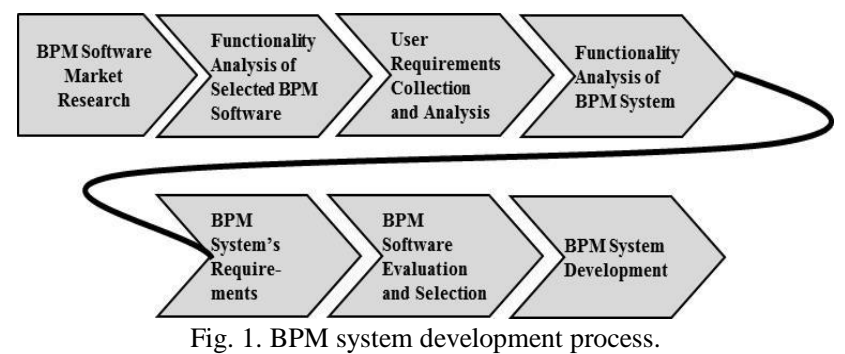

\section{A. BPM Software Market Research}

The first methodological step includes the identification most of available BPM software and the creation of a short list of software packages.

An extensive market research was conducted and the BPM software was evaluated, based on a set of criteria: availability of source code (open source), focus in Public Sector services, previous application in other Greek Public Sector's projects, increased market share, good evaluation in benchmarking reports, frequent reference in the studied literature.

The Intalio BPMS and Adonis BPMS as well as jBPM were shortlisted, as they all met the above requirements. Intalio is highly scored in the evaluation reports [22], [23] and it has been used in similar projects of the Greek public sector [24] and it has increased involvement in the public sector abroad [25]. Adonis was chosen because it has been previously used for business process modeling in the Greek public sector like the LGAF project [26], has received great reviews in various case studies [27], and advertises that the free version offers a complete BPM software solution. Finally, jBPM was selected as it is the market leader in open source BPM software, it is placed among the top open source BPMS in the majority of the case studies, and its latest version supports the graphic standard BPMN 2.0 (in the BPMS selection for the LGAF project it was rejected due to the lack of BPMN 2.0).

\section{B. Functionality Analysis of Selected BPM Software}

The second methodological step includes the detailed description of BPM software functionality and the creation of the list of all available features.

An in-depth analysis of the offered functionality of the shortlisted software was performed in order to fully understand how the selected software operate, and acknowledge which of the offered functionality can be utilized in the subsequent steps of designing the BPM system, Data was collected via the software companies' websites, brochures and user manuals, web forums and extensive evaluation reports. This analysis included detailed architectural structure illustration and a break-down analysis of the software's functionality, presenting for each component and tool separately a list of all the available features and functions.

\section{User Requirements Collection and Analysis}

The third methodological step includes the conduction of a set of interviews with users in Municipalities. Several interviews with the BPM system's potential users were conducted. For the interviews' needs, structured questionnaires were designed, in order to record the operational functions of the Municipalities (as regards the monitoring of business processes) and to capture indicative processes (as regards the presentation of the processes' flow). Moreover, a detailed presentation from the project's development team was performed, as to demonstrate the potential functionality of the system and share the team's experience in BPM. Finally, the system's functionality and usability was captured both by the project's team and system users.

\section{Functionality Analysis of BPM System}

In order to perform the BPM system's functionality analysis, it was essential to define the functional blocks and user roles. The fourth methodological step includes the definition of user roles and responsibilities and the identification of functional blocks of the system (Fig. 2).

BPM system's stakeholders were split into four roles:

- Supervisor: Supervisor of the BPM system is the Mayor of the respective municipality or his personal advisor. The role requires a broad knowledge of municipality's processes and services, as also a high level of business knowledge. On the contrary, there is no need for any technical knowledge regarding the software and tools used in the process management. Supervisor is responsible to develop strategies, define operational goals and roles and to check the services' performance. Due to the nature of the role, Supervisor has oversight and access to the whole System, placing greater emphasis on the report results.

- Power User: The role of the Power User undertakes an employee with high level knowledge of BPM and basic technological background, as it is necessary to be familiarized with BPM software and tools. He is responsible for modeling, simulating and redesigning of business processes, exporting result reports and integrating data with the Benchmarking system. Power User is the orchestrator of the BPM system. 
- Administrator: The role of Administrator undertakes an employee with high technological background and understanding of the BPM's principles and concepts. The role requires familiarity with process modeling information systems and application development frameworks. He is responsible for the configuration of the processes and user interfaces, the definition of roles and operational stages within the system, the setup of custom reports and the functionality of the system's interfaces.

- User: The role of (normal) User has municipal officials involved in the business processes of the municipality. There is no requirement of any technological or operational knowledge, but it necessary to be familiarized with computers. Users interact with BPM system through a web-based user interface, where they see their assigned activities, the processes' status in which they participate and the final result reports, as well as they can add data to selected fields.

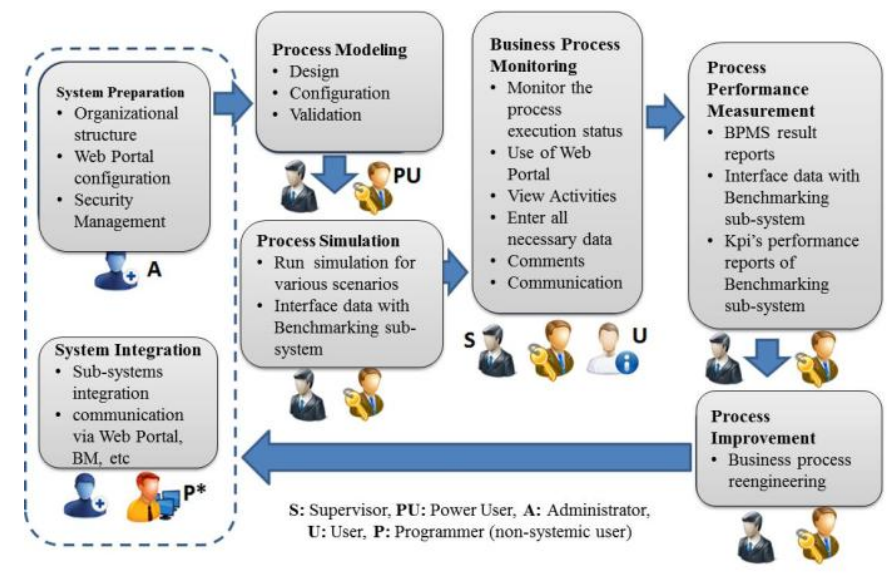

Fig. 2. Functional blocks and roles of BPM system.

BPM system's functionality consisted of a cyclic sequence of seven functional blocks. At the initial stage of development the system's preparation is being performed. This involves the organizational structure and business rules mapping, the web portal's configuration and the security management. Then, the separate components which constitute the BPM system are being integrated, along with the Benchmarking system. Subsequently, the business processes are modeled, as they are designed and configured. After a validation that the processes are properly modeled and are executable, multiple simulations are performed. The data results are exported to the Benchmarking system in order to measure the process's performance via KPI's and result report is interfaced back to the BPM system. At this stage, the optimal processes are executed while the users take advantage of the web-portal's functionality in order to monitor the process's execution status and enter all necessary data. After a process execution has been completed, the BPM system exports the appropriate data to the Benchmarking system, as to measure the process's performance and export back to the BPM system detailed measurement reports via KPI's. Finally, reporting results are examined by the Power User and if that is deemed necessary, the processes are improved, through business process reengineering. Fig. 2 illustrates the described functional blocks of the BPM system and the involvement of the

\section{different roles.}

\section{E. BPM System's Requirements}

The fifth methodological step includes the description of system's use cases per user role and functional block and the detailed presentation of system's requirements. 19 use cases were created, which were further categorized per user role and functional block. Table I presents all use case scenarios (and the involved system roles). In each of those, an extensive functionality analysis was performed in order to depict each user's system tasks and responsibilities. Furthermore, all use cases were drilled down into functional requirements that the BPM system should support.

TABLE I: USE CASE SCENARIOS PER FUnCTIONAL BLOCK

\begin{tabular}{|c|c|c|}
\hline Functional Blocks & Scenarios & System role \\
\hline $\begin{array}{l}\text { System } \\
\text { Preparation }\end{array}$ & $\begin{array}{l}\text { 1: Organizational structure } \\
\text { 2: Web portal configuration, } \\
\text { 3: Security Management }\end{array}$ & Administrator \\
\hline System Integration & 4: Sub-systems integration & Administrator \\
\hline \multirow{2}{*}{ Process Modeling } & 5. Process Configuration & Administrator \\
\hline & 7: Process Modeling & Power User \\
\hline $\begin{array}{l}\text { Process } \\
\text { Simulation } \\
\end{array}$ & 8: Process simulation & Power User \\
\hline \multirow{3}{*}{$\begin{array}{l}\text { Process Execution } \\
\& \text { Monitoring }\end{array}$} & 10: Process Monitoring & $\begin{array}{l}\text { Supervisor, } \\
\text { Power user }\end{array}$ \\
\hline & $\begin{array}{l}13: \text { Communication with other } \\
\text { Users }\end{array}$ & Supervisor \\
\hline & $\begin{array}{l}\text { 14: View Activities } \\
\text { 15: Enter all necessary data } \\
\text { 16: Comments, report a } \\
\text { problem }\end{array}$ & Users \\
\hline \multirow{3}{*}{$\begin{array}{l}\text { Process } \\
\text { Performance } \\
\text { Measurement }\end{array}$} & 6: Create Reports & Administrator \\
\hline & 9: Use Reports & $\begin{array}{l}\text { Supervisor, } \\
\text { Power user }\end{array}$ \\
\hline & $\begin{array}{l}\text { 11: Interface data with } \\
\text { benchmarking subsystem }\end{array}$ & Power user \\
\hline $\begin{array}{l}\text { Process } \\
\text { Improvement }\end{array}$ & 12: Process reengineering & Power user \\
\hline
\end{tabular}

Based on the use cases analysis, detailed requirements of the system's functionality were set. The requirements were presented in the form of lists, which features three level of analysis:

- The first level of analysis relates to the stages of the system (e.g. 1. System Preparation)

- The second level of analysis refers to the system's use cases. (e.g. 1.1. Organizational Structure or 1.2.Web Portal Configuration)

- The third level of analysis separates the tools or components used by the functional features thereof (e.g. 1.1.1. Tools (Business Rules Management Tool, User Directory, etc)).

\section{F. BPM Software Evaluation and Selection}

The sixth methodological step includes the software selection by research team experts, based on BPM system's requirements of previous steps.

The shortlisted BPM software packages resulted from the second methodological step, were evaluated in order to select the most suitable software for the implementation of the project's BPM system. The tools and functions of the shortlisted BPM software, as were thoroughly analyzed in the second methodological step, were cross-checked with the BPM system's requirements (resulted from the fifth step) to 
determine to which extent they cover the system's needs. Succinctly, the commercial version of Intalio BPMS offers the richest features, as it provides with plenty and powerful tools that cover the most complex operational needs. On the contrary, Intalio's free version proved to be inadequate to the stated requirements, as it comes only with the modeling tool and server. Adonis BPM offers powerful tools for the process modeling and simulation phase, but it lacks the compelling features in the rest functional blocks. jBPM proved to be the best software, as it offers the majority of the system's features for free and it is fully open source, which favors the development of applications and the system's configuration.

Additionally, the shortlist of BPM software solutions was evaluated from a user experience standpoint. The software was installed in a local computer and was used to model and simulate selected business processes of the Municipality of Marousi (e.g. the process: P1.3: "Issuance of Certificate for Property Tax Payoff).

Overall, Intalio proved to be a very comprehensive modeling software, as it provides all the necessary features to design business processes, it is very user friendly and performed flawlessly. jBPM offers most of the necessary functions, but presented specific difficulties both during installation and use. Finally, Adonis proved to be the least appropriate software, as it lacks some modeling notations and features.

\section{G. BPM System Development}

The seventh methodological step includes the development of the system, based on the functionality of the selected software, as well as its integration with other subsystems.

The application of the previously described methodology led to the BPM system's requirements, as well as to a proposal regarding the software package that will be implemented in the next phase of the project. The final decision about the software solution was made after their evaluation from a user experience standpoint, in cooperation with the system's developers, in order to reinsure the implementation of the requirements. Additionally, the BPM system's integration with the rest subsystems was taken into consideration.

Finally, jBPM was selected for the development of the BPM system, as it provides great versatility due to its open source code, and offers all the essential tools for the implementation of the system's requirements.

\section{BPM SYSTEM FUNCTIONALITY AND INTEGRATION WITH BENCHMARKING SYSTEM}

As illustrated in Fig. 3, BPM system consists of five core components: a Process Designer which is used for process modeling and performance of simulation scenarios, executed in the Process Engine, a User Directory Management component to manage user accounts, a Process Analytical Reporting component to provide the necessary process performance reports, and a Process Monitoring and Exception Handling module to deal with real time information about the processes' execution and to intervene when deemed necessary. Those components are integrated with the existing IT infrastructure, as also with databases, where business rules and processes' data are being stored and recovered.

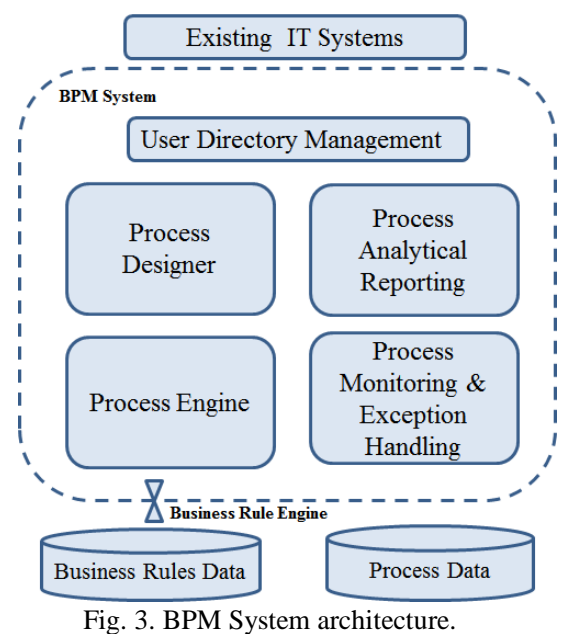

BPM system is ntegrated with Benchmarking system and two other peripheral systems of the "PSP-DMEP" platform. The integrated system (PSP-DMEP) is consisting of four systems that are described below and graphically represented in Fig. 4.

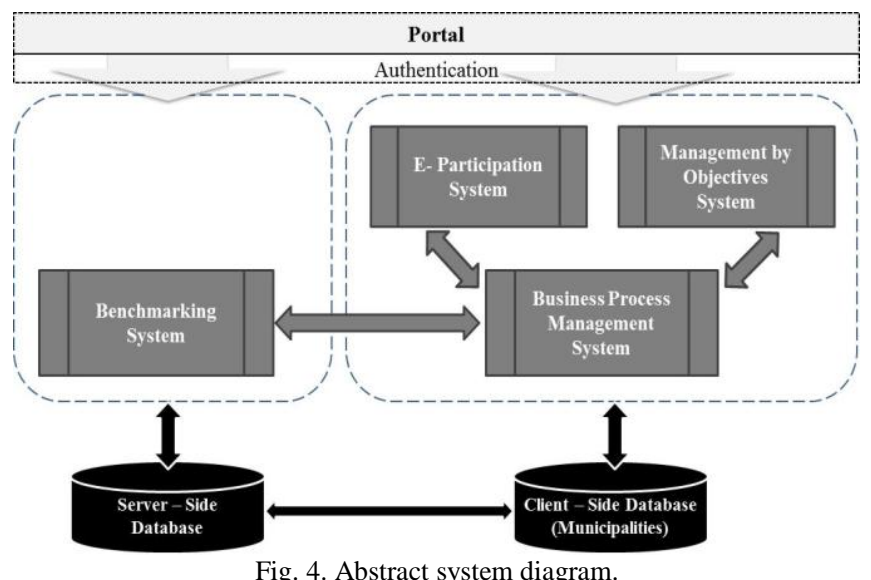

Benchmarking system performs all the necessary data manipulations for performance measurement and benchmarking across and within municipalities based on its smart performance evaluation algorithm. Benchmarking is expected to enhance transparency and provide a basis for improved effectiveness and efficiency. Performance indicators are directly linked to the business processes in the Business Process Management System (BPMS). BPMS provides functionality for process / service analysis, design and redesign. The process models prepared can be dynamically executed with the embedded simulation tool and the simulation results can be fed back to the Benchmarking system. In that way, the results of an in vitro new process process/service execution can be tested and the impact on performance can be evaluated. The Management by Objectives module (MBO) provides the necessary documentation and design tools for supporting the implementation of Management by Objectives, as stipulated by Greek Law (Act. 3230/2004). Law No. 3230/2004 sets out the rules for implementing the "Management by Objectives System" in Greek public sector, measuring the efficiency and effectiveness of the public sector, assessing the results and 
formulating specific proposals for its qualitative improvement [28]. Finally, the e-Participation system constitutes the 'eyes and ears' of the system to the external environment, and it's in essence a gateway to the municipality portal enabling citizens to get informed and participate actively in the decision making process and policy development of the administration. It includes functionality, such as public dialogue and consultation, complaint management, live streaming of municipality assemblies, forum, polls and surveys.

The overall system guarantees secure storage for information and access only by authorized personnel, using roles with classified access rights. Furthermore, it aims to introduce advanced technological capabilities (e.g. process modeling and simulation for process redesign) in an easy and understandable way, providing simple user interfaces. The new system aims to enhance accountability and discipline in municipalities but also to enhance knowledge conversion processes (through the MBO and Benchmarking systems), stimulate creativity by expanding the boundaries and including more actors (through the e-Participation system) and stimulate exploration activities (through the BPMS).

The technical solution of the described system is depicted in Fig. 5. It includes MySQL database, JBoss, Liferay portal, JBPM and Drools tools and applications, as well as some custom Java apps. The portal uses Tomcat and Apache tools for user authentication and role management. Using these tools, the integrated system (PSB-DMEP) is being developed and it will be evaluated by the users in Municipalities.

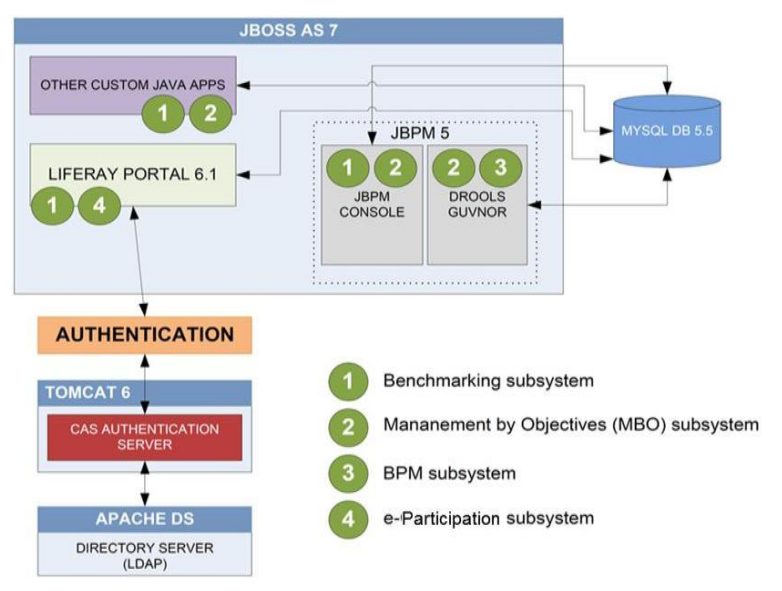

Fig. 5. Technical solution of the integrated system.

\section{CONCLUSIONS AND FURTHER WORK}

The presented BPM system is the core system of an integrated web-based information system for benchmarking, design, monitoring and evaluation of public services. The methodological steps followed (Fig. 1), were appropriate for effective requirements analysis and design specifications of the BPMS, incorporating:

- Functionality analysis of existing BPM software in relation to user requirements analysis extracted from interviews with the staff of different local government organizations.

- Detailed analysis of system's functional specifications and required system roles (in relation to existing or required organizational roles of the municipalities under consideration).

- Development of several use case scenarios that describe the needed functionality of the BPM system and its interoperability with the other systems constituting the integrated information system developed in the research project.

- Pre-selection of BPM software and utilization of user experience of specific software solutions that met system's requirements so as to select the most appropriate technical solutions.

The described methodological approach concludes to the development of a BPM system for public sector. Its usefulness in business process design and reengineering, include:

- Achieve increased effectiveness and efficiency of the back office and front end business processes executed, as processes and the outcomes of the public services are measured, evaluated and benchmarked with various public agencies.

- Ensure that regulations and policies are compiled across the organization.

- Enhance the process transparency and the staff's level of responsibility and accountability.

- Offer flexibility to the constant changes in regulation frameworks.

- Guarantee safe storage for sensitive information and their access only by authorized personnel, using roles with classified access rights.

- $\quad$ Reduce operational costs and improve productivity by integrating process steps and replacing manual records that affect specific performance measures.

- Achieve optimization of public services, through analysis, simulation and benchmarking of the various instances of the business processes.

- Leverage new IT technologies to public sector in an easy and understandable way, favoring innovation and adopting best practices of private sector.

BPM system is under development and it is expected to be completed in accordance with the design and the specifications resulted from the methodological approach followed. Next, BPM system and the other three systems of the integrated information system being developed under the research project, will be tested, evaluated and accepted by the users of Municipalities while corrective actions will conclude to the productive version of the system.

Further research includes the development of a structured approach for system dissemination and utilization in other organizations of Greek public administration, besides these municipalities that contribute the research project. Extending system's usage and usefulness to other organizations will enforce the system and will enhance its functionality in order to cover a broader set of potential users in public sector.

\section{REFERENCES}

[1] L. Mizell, "Promoting performance-using indicators to enhance the effectiveness of sub-central spending," OECD Publishing, 2008.

[2] P. Micheli and M. Kennerley,"Performance measurement frameworks in public and non-profit sectors," Production Planning \& Control, vol 16, no. 2, pp. 125-134, 2005 
[3] A. Greasley, "Using process mapping and business process simulation to support a process-based approach to change in a public sector organization," Technovation, vol. 26, no. 1, pp. 95-103, 2006.

[4] C. Richardson, C. Moore, C. Le Clair, and R. Vitti. (24 August, 2010). The forrester wave: business process management suites. Q3 2010 [Online].

Available: http://www.idevnews.com/images/emailers/110415_ProgressWhitePa per_EU_Kathy/2010-forrester-wave-bpm.pdf

[5] Oracle Inc. (2013). Increasing efficiency and responsiveness - BPM in the public sector. [Online]. Available: http://www.oracle.com/us/technologies/bpm/bpm-public-sector-soluti on-brief-1913986.pdf

[6] J. P. P. Ravesteyn and J. Versendaal, "Success factors of business process management systems implementation," in Proc. 18th Australasian Conf. on Information Systems (ACIS), Toowoomba, 2007.

[7] Z. Ning and H. Xiaowei, "Government process management under electronic government and its application," in Proc. 2011 International Conf. on E-Business and E-Government (ICEE), 2011

[8] L. Sullivan, L. Kelly, and D. Olson, "Defense enterprise planning and management," in Business Process Engineering: Advancing the State of the Art, Elzinga, D. J. et al., Eds., Kluwer Academic, Boston, MA, 1999.

[9] F. Corradini, D. Falcioni, A. Polzonetti, and B. Re, "Innovation on public services using business process management," in Proc. International Conf. on E-business, Management and Economics IPEDR, 2011, vol. 25.

[10] P. Harmon. Danish municipalities case study. (2010). [Online]. Available: http://www.bptrends.com

[11] P. Wohed, D. Trufflet, and G. Juell-Skielse, "Business process management for open e-services in local government experience report," Lecture Notes in Business Information Processing, vol. 81, pp. $1-15,2011$.

[12] I. Sanderson, "Performance management, evaluation and learning in 'modern' local government," Public Administration, vol. 79, no. 2, pp. 297-313, 2001

[13] K. M. Eisenhardt and J. A. Martin, "Dynamic capabilities: What are they?" Strategic Management Journal, vol. 21, pp. 1105-21, Oct.-Nov. 2000.

[14] C. Wang, "Ahmed PK dynamic capabilities: A review and research agenda," Int J Manag Rev, vol. 9, no. 1, pp. 31-51, Mar. 2007.

[15] OECD, OECD Skills Outlook 2013, Paris: OECD Publishing, 2013.

[16] G. Deleuze and F. Guattari, A Thousand Plateaus: Capitalism and Schizophrenia, London: The Athlone Press, 1988

[17] I. Nonaka, "A Dynamic theory of organizational knowledge creation," Organization Science, vol. 5, no. 1, pp. 14-37, 1994.

[18] B. Regnell, "Requirements engineering with use cases - A basis for software development," Ph.D. Thesis, Department of Communication Systems, Lund Institute of Technology, Lund Univ., Sweden, 1999.

[19] Y. Chen, "Enterprise modelling for participative business process reengineering," Ph.D. Thesis, University of Warwick, Department of Computer Science, Coventry, UK, 2001.

[20] A. P. Sage, Systems Engineering, John Wiley and Sons, Inc., New York, NY, 1992

[21] D. Morris, G. Evans, P. Green, and C. Theaker, Object Oriented Computer Systems Engineering, London: Springer-Verlag, 1996.

[22] J. Sinur and J. Hill. (2010). Magic quadrant for business process management suites. Gartner Inc. [Online]. Available: http://agileelements.files.wordpress.com/2010/10/gartner-2010-bpms _-magic_-quadrant.pdf

[23] C. Richardson and D. Miers. (11 March, 2013). The forrester Wave: BPM suites. Q1. Forrester Research Inc. [Online]. Available: ibm.co/ZWp086

[24] KEDKE. (2008). Local Government application framework (LGAF) business Process management system. Project's deliverable of component $\mathrm{Nr}$.2, central union of municipalities and communities of Greece (KEDKE). Available: http://gaf.kedel.org/wiki/resource/section/Paradotea_ComponentNo2

[25] Intalio Inc. (2013). Process management (BPM) success stories. [Online].

Available: http://www.intalio.com/products/bpms/success-stories

[26] P. Belsis, S. Gritzalis, C. Skourlas, I. Chalaris, and A. Malatras, "Distributed Processing For Knowledge Management Purposes In Cooperative E-Government Environments," International Scientific Conf. eRA-2, September 22-23, 2007, Athens, Greece.
[27] O. Glassey, "A case study on process modelling - Three questions and three techniques," Decision Support Systems, vol. 44, no. 4, pp $842-853,2008$.

[28] I. Tsimboukidou, P. Dionysopoulou, and J. Mylonakis "Total quality management systems in the Hellenic Public Administration: A case study on the common assessment framework application," Public Administration Research, vol. 2, no. 2, 2013

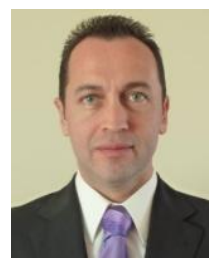

Sotiris P. Gayialis has a degree in mechanical engineering and a $\mathrm{PhD}$ degree from National Technical University of Athens, with emphasis in business process management, supply chain management and information systems. He is a teaching and research associate at National Technical University of Athens (NTUA). He teaches operations management and management information systems. He also teaches business administration at Hellenic Open University since 2011. He has experience in management consulting since 1997 . He has participated in 30 research projects at NTUA and 20 projects as a business consultant. His research interests, professional skills and publications are related in the areas of business process management, enterprise modelling, industrial management, supply chain management, enterprise resource planning systems and management information systems. He has published more than forty papers in peer reviewed journals, book chapters and conferences. He is also a co-author of the book entitled "Business process management: engineering, reengineering and improvement". His published work has more than 300 citations and he is a reviewer in various scientific journals, like European Journal of Operational Research and Enterprise Information Systems.

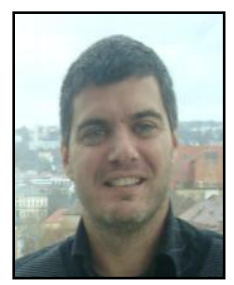

Georgios A. Papadopoulos is a teaching and research associate at National Technical University of Athen (NTUA). He has a degree in mechanical engineering and a $\mathrm{PhD}$ degree from the National Technical University of Athens in Production Planning and Control, and a master degree in business administration (MBA) from University of Wales, UK His research interests include production planning, supply chain management, management information systems, with focus in logistics and warehouse management. His research has been published in international journals and conferences. He has participated in research projects, in the subjects of reengineering using modeling and simulation, developing business model for the extended enterprise, developing a detailed production scheduling system integrated with ERP software and implementation of plant maintenance system with emphasis on breakdown prevention and machine productivity augmentation.

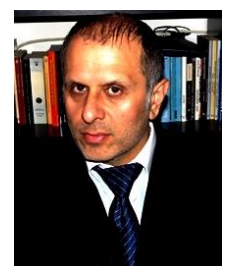

S. T. Ponis is an assistant professor at National Technical University of Athens (NTUA). He has a degree in mechanical engineering and a $\mathrm{PhD}$ degree from the National Technical University of Athens. He teaches supply chain management with an emphasis on technology systems (SCM/e-business systems). His publications include book chapters, papers published in fully reviewed scientific journals, scientific papers presented in international conferences (double blind review system), lecture notes and presentation for the support of the educational process in NTUA His research interests are traditionally resided in the areas of production planning and control, operations research, supply chain management, business process modelling, networked and virtual enterprises, and the information systems that support all the above. He has been appointed from the European Union as an expert reviewer in two different research units. He has monitored, evaluated and finally approved the works of two large European Projects. He is also an expert reviewer for the General Secretariat of Research and Development, the Greek Information Society S.A, the Institution to Promote Research of Cyprus and the Czech Science Foundation

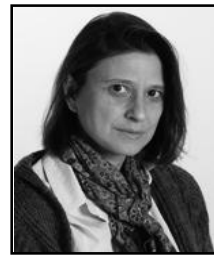

P. Vassilakopoulou is currently a researcher with the University of Oslo, Department of Informatics. She studied industrial engineering in Technical University of Crete) and operations research in Columbia University, School of Engineering \& Applied Science, Fulbright Scholar and obtained her PhD degree from the National Technical University of Athens on Work Organisation and Information Systems. Prior to joining NTUA for PhD studies, she was a management consultant for over a decade. Her work is centred around the design of ICT enabled interventions in work 
systems with a focus on the services sector (healthcare and financial services). She has a continuing interest in studying the interplay between the organized delivery of technological capabilities (to support situational control, transformation processes and coordination) and individual coping efforts within and across institutional contexts. Her research work up to today falls within three key themes: studies on the appropriation and use of technology, studies on design initiatives exploring the adoption of user oriented approaches and studies on efforts to reform complex sociotechnical work settings through the "information infrastructures lens.

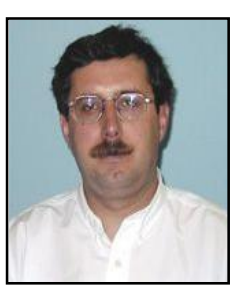

I. P. Tatsiopoulos is a professor in operations management and logistics at the Industrial Management and OR Sector of the National Technical University of Athens (NTUA) and the chairman of the Board at EPA ATTIKI. He is the chairman of the MBA Program "Athens MBA", which is co-organised by NTUA and Athens University of Economics and Business. He studied mechanical and industrial engineering at NTUA in 1978 and followed post-graduate studies at the TH Aachen, Germany and the University of Lancaster (UK) under a NATO grant. He holds a PhD degree in 1983 in operational research from the University of Lancaster. He has been a member of the Senate of NTUA, the vice-chairman at European Management Association, a member of the Board at Hellenic Management Association, the chairman at Institute of Production Management at Hellenic
Management Association. He serves in the editorial board of the Production Planning \& Control Journal. He has been active for several years as a professional production engineer in both industrial and consulting firms and he has been project coordinator in several research projects. His academic interests revolve around the areas of industrial management, computer-aided production management, manufacturing information systems, production system design, enterprise resource planning systems, decision support, logistics and supply chain management including the aspects of energy supply, procurements, business process management and reengineering and benchmarking methodologies. 